\title{
Cutting without Cursing: A Successful Cancellation Project
}

By Beatriz Betancourt Hardy, Martha C. Zimmerman, and Laura A. Hanscom

\section{Authors:}

Beatriz Betancourt Hardy, Dean of Libraries and Instructional Resources, Salisbury University, 1101 Camden Ave, Salisbury, MD 21801, bbhardy@salisbury.edu, (fax) 410-543-6203, (office) 410-543-6133

Martha C. Zimmerman, Associate Dean and Director of Collection Management, Salisbury University, 1101 Camden Ave, Salisbury, MD 21801, mczimmerman@salisbury.edu, (fax) 410-543-6203, (office) 410-677-0110

Laura A. Hanscom, Scholarly Communications Librarian, Salisbury University, 1101 Camden Ave, Salisbury, MD 21801, lahanscom@salisbury.edu, (fax) 410-543-6203, (office) 410-543-6206

\begin{abstract}
The Salisbury University Libraries embarked on a serials and database cancellation project in the 2014-2015 academic year, eventually cutting nearly $20 \%$ of journals without causing any faculty protests. Picking up ideas from numerous other libraries, the three-person project task force developed a three-stage process: 1) preparation-gathering data and laying the groundwork for getting feedback; 2) getting feedback from liaisons, faculty, and departments; and 3) making decisions about what to cut and sharing the results. This article details the steps taken and key recommendations for other libraries undertaking similar projects.
\end{abstract}

Keywords: Cancellation projects, serials cancellation, collection management, budget cuts 


\section{Introduction}

Cutting journals and databases is neither popular nor easy, yet sometimes it simply has to be done. That was the situation faced by the Salisbury University Libraries in late 2014. Learning about how we succeeded in cutting costs nearly $20 \%$ without arousing the ire of the faculty may prove helpful to other libraries undertaking a similar project.

\section{Background}

Salisbury University (SU) is a highly-ranked public regional comprehensive university on Maryland's Eastern Shore. With 8,090 full-time equivalent (FTE) students, it features strong programs in nursing and other health sciences, social work, education, business, and biology, with a growing number of courses offered online. SU emphasizes undergraduate research and experiential learning, and the 497 FTE faculty are excellent teachers and mentors. While SU offers two doctorates and 14 master's degrees, the graduate students number only 773.

The SU Libraries comprise the main library, Blackwell Library; the Edward H. Nabb Research Center for Delmarva History and Culture; and the Curriculum Resource Center. The staff is relatively small for a university this size, 28 full-time staff, including 15 faculty librarians. The Libraries have a robust liaison program, with most faculty librarians serving as liaisons to several academic departments. The liaisons are responsible for instruction, collection development, and research support for their departments. The collections also are relatively small, because Blackwell Library long ago ran out of collection space. The Libraries owned 294,282 books and maintained 1,016 journal subscriptions at the beginning of the 2014-2015 academic year. However, the Libraries' participation in the University System of Maryland and Affiliated Institutions consortium provides our users with quick access to much bigger collections. 
Like many universities, SU's budget has suffered since the 2008 recession, and consequently, the Libraries' budget also has suffered. For several years, the Libraries cut other areas of spending even as spending on journals and databases increased due to spiraling prices and faculty requests. Nonetheless, in the 2014-2015 academic year, it became apparent that we could no longer avoid cutting journal and database spending. The dean of libraries, the director of collection management, and the scholarly communications librarian formed a task force to carry out a cancellation project. We established a goal of $20 \%$ or between $\$ 150-175,000$. The rest of this article will detail how we carried out the project and the lessons we learned.

\section{Literature Review}

Librarians have been recounting their experiences with serials cancellation projects since at least the 1980 s, sharing their processes and offering warnings and advice to others. The context has changed quite a bit with the transition to electronic journals and more robust usage statistics, but many of the basic principles remain the same. This overview will focus on the articles we found helpful rather than summarizing all the articles that are available.

In 1992, Paul Metz, principal bibliographer at the University Libraries at Virginia Tech, published an excellent piece, "Thirteen steps to Avoiding Bad Luck in a Serials Cancellation Project." He laid out the many steps that Virginia Tech took in cutting more than 1,250 serials. While some of what he has to say is dated, the steps themselves make a great deal of sense. One idea we picked up from him was to have librarians nominate titles for cancellation and have faculty react rather than asking the faculty to nominate titles, which “invites delays, nominations of dead titles or titles that don't add up to much money, and bias on the part of the self-nominated individuals willing to take the lead." Another key 
suggestion he made was to nominate more titles than needed, so that some titles can be magnanimously spared. ${ }^{1}$

In 1993, an article by Suzanne Wise, reference librarian at Appalachian State University, was helpful in that her university is very similar to Salisbury, a regional comprehensive with a relatively small staff. One bit of advice she gave which struck a chord with us was to "develop a list of service priorities and follow them in decision-making. These priorities should conform to the mission of your institution. In our case, occasional use by faculty was not deemed as important a factor as frequent use by undergraduate students."2

In 2000, Janice Jaguszewski and Laura Probst, collections coordinators at the University of Minnesota, detailed how electronic resources affected serial cancellations and remote storage decisions. While their focus on large academic research libraries had little relevance for us, their discussion of the complexities of evaluating electronic resources resonated with our situation. Among the criteria they cited are competition among vendors, consortial arrangements, and archiving options. These criteria informed both our data collection and our decision-making, with competition among vendors being especially important for us in regards to databases and consortial arrangements and archiving being especially important in regard to journals. ${ }^{3}$

An article published in 2005 proved especially important for our efforts at getting faculty input. Ronadin Carey, Stephen Elfstrand, and Renee Hijleh, all of the University of Wisconsin-Eau Claire, described their library's strategy for involving the faculty and thereby gaining acceptance for a $15 \%$ cut in serials spending. While we did not attempt to use the $\operatorname{CORE}^{\circledR}$ Project Management Method, the formal project management system that UW-Eau Claire used, we did find the steps they took to get input useful. One 
important point they made was that it was important to not just collect data but present it to the faculty in a useful way, or, as they put it, "The task was to transform data into information."

In 2010, Ryan Weir, serials and electronic resources librarian at Murray State University, laid out a planning process for serials cancellation projects at small- and medium-sized academic libraries. He emphasized the importance of "developing a strategic plan to address the budget shortfalls and having an effective communication plan" both for internal communication within the library and for external communication with stakeholders. $^{5}$

Not officially part of the literature but equally important in influencing how we went about our project were the websites other academic libraries established for their serials cancellation projects. From the University of North Carolina-Wilmington's 2009 project, we picked up a simple rating system for individual faculty to use: essential, useful, minimally useful. We also found the schedule and FAQs helpful. ${ }^{6}$ Colgate University's 2009 project website included a copy of the letter liaisons used to share proposed cancellations with department chairs; we liked the idea of having departments as a whole rank the proposed cancellations rather than relying simply on individual faculty feedback. ${ }^{7}$ From N.C. State's 2014 project, we adopted the idea of having an online web form for faculty feedback. ${ }^{8}$ The University of Nevada-Las Vegas Libraries created an excellent website for their 2014 project that gave us ideas for what to include in our own website.

\section{Process}

The literature review helped us develop an outline for how to carry out the journal/database project. We filled in some details as we proceeded. The project basically fell into three stages: 
1. Preparation, including both gathering data about our journals and databases and laying the groundwork for getting feedback.

2. Getting feedback, initially from the librarian liaisons and then from faculty and departments.

3. Making the decisions about what to cancel and sharing the results.

\section{Preparation: Data Sources \& Collection}

Historically, the serials librarian was responsible for the maintenance of the serials collection and the collection of serials usage and a research and instructional services librarian was responsible for database renewals and the collection of database usage statistics. Simultaneous resignation and retirement of the individuals in these positions paved the way for merging these functions into a new position: serials and electronic resources librarian. Unfortunately, all hiring at Salisbury University was frozen when the need for the cancellation project arose. Therefore, collection of usage statistics and organization of the data fell to the director of collection management, assisted by the scholarly communications librarian.

The dean considered the scholarly communications librarian a good choice to help with this cancellation project in the absence of a serials and electronic resources librarian because of her knowledge of the ever-increasing costs of journal subscriptions. Also, as a librarian liaison herself, she served as a point of contact for the other liaisons to answer questions about the project overall, how the data was collected, and how the liaisons were to assist their departments in reaching the goal of cutting $20 \%$ of the journal budget.

The first step in data collection involved changing the administrative contact for databases and e-journal platforms from the previous individuals to the director of collection management. As she accomplished 
this, she also gathered usage statistics. For e-journal analysis, she found that EBSCO, the Libraries' subscription agent, provides excellent tools for data collection. She used EBSCONet and data stored in EBSCO's Usage Consolidation tool in addition to data on individual platform sites. For print journals, she relied on in-house usage statistics that are collected regularly and recorded on the Libraries' intranet. For databases, she gathered statistics from OCLC, Lyrasis, the EBSCO Administration module, SFX Collection Management, and individual platform sites.

The data collected from this wide variety of sites were, predictably, widely variable:

1. Some sites were COUNTER compliant, though not all at the same level.

2. Terminology lacked consistency across sites, but most sites with robust statistics provided a glossary defining what it was they were counting.

3. Terms were in no way uniform even across sites supposedly utilizing the same standard.

4. Some sites provided data but did not comply with any industry standard.

5. Some platforms/databases did not provide online access to data, requiring contact with a customer service representative.

In order for the study to be useful, the data had to be comprehensible to non-technical librarians and faculty, as well as truly comparative. Because Salisbury uses Microsoft products as standard software, we chose to create an Excel spreadsheet to share with the faculty. The director of collection management met with the technology librarian to discuss what data elements were the most useful to collect and compare. For databases, the data elements they chose were Searches/Sessions/FullText/Abstracts. The director of collection management created a spreadsheet of all non-consortial subscription databases to record these data elements for FY2014, covering July 1, 2013-June 30, 2014. A Notes column contained information for specific databases, such as "Abstracts = TOC Views," 
"Events," and "Only searches reported." This spreadsheet also included columns for Title, Package (if applicable), Provider, Payment Details, Consortium, Cost, and Cost per Search. While a comparison of multiple years of usage would have yielded more reliable results, the time-frame of the study did not allow this comparison.

Data elements for the journal master spreadsheet were simpler, being divided into print usage and online usage. Though simpler, this data were less reliable. While print usage statistics went back many years, we relied on only the two most recent calendar years for comparison with online usage. We recognized that print usage statistics for journals are always highly suspect. Despite signs asking patrons not to re-shelve print journals they have used, very few patrons leave their journals on the re-shelving book trucks. Items left on the re-shelving trucks may be moved before being counted and re-shelved by serials staff. Patrons sometimes deliberately mis-shelve journals they are using to ensure access at a later time or date. Unfortunately, despite its problems, these were the only data we had for print usage. The director of collection management compiled and entered these data in the master spreadsheet.

For electronic journals, EBSCO Usage Consolidation provided online usage data for the past two calendar years. Since Salisbury had not activated all e-journals in Usage Consolidation, we also relied on individual platform data. The scholarly communications librarian handled collecting and entering this data.

The journal master spreadsheet contained these data elements: Title, Print ISSN, Online ISSN, Format, Start Date, Fund Code, Cost: Current, Usage 2014, Cost per Use: 2014, Cost: 2013, Usage 2013, Cost per Use: 2013, Total Usage, Average Cost per Use, Usage from (Database or Platform), Notes (membership/package/etc.). The director of collection management also screened the original list of 
titles for memberships, package titles, and titles on the Maryland Shared Distributed Journal Collections list. This allowed us to identify titles not eligible for cancellation or titles bundled together and not available for individual action.

\section{Preparation: Laying the Groundwork for Getting Feedback}

Even as the director of collection management and the scholarly communications librarian collected data, the dean of libraries began preparations for getting feedback. She met with the Deans' Council, consisting of all academic deans and the provost, to solicit ideas for how best to communicate with the faculty. She called a meeting of the Library Committee, a Faculty Senate committee with representatives from each of SU's four schools, to inform them about the project and hear their thoughts about what information the faculty would need and how best to solicit feedback from the faculty.

As a result of these meetings and the experiences of the data collectors, the project task force drew up a timeline and made some key decisions:

1. We would only ask librarian liaisons and not academic faculty to provide feedback on databases. We thought it would be too complex to explain what page views, TOC views, etc. meant to people not familiar with library jargon, especially since the data were not entirely consistent from database to database.

2. We would ask the librarian liaisons to narrow the lists of journals for each department to only those titles we would seriously consider cutting, aiming for about $25 \%$ of the costs overall. We only were intending to cut $20 \%$ from the budget, but we wanted to have some flexibility while not including so many titles as to set off panic. We knew there were some titles that were required for accreditation, received heavy use, or were the basis for class assignments that we 
simply were not going to cut. There was no reason to get the faculty riled up about those being potentially cut when in reality that was not going to happen.

3. We would provide individual faculty the opportunity to comment on not only their own department's journals but any journals that were being considered for cancellation. Given the interdisciplinary nature of much research and teaching at SU, this was important.

4. To ensure that we understood each department's priorities, not simply those of individual faculty, we would ask each department chair to provide a departmental response, gathering that information by whatever means-a departmental meeting, a poll, or whatever-the chair considered appropriate.

5. We also decided that we would call this a journal review project rather than a serials cancellation project. First, it was clear from the meeting with department chairs that faculty did not really understand what we meant by serials, but they understood what journals meant. Second, calling it a review made it seem less painful. It also allowed the possibility that if faculty wanted to cancel additional titles beyond what we were asking them to cut, they could subscribe to new titles. While no one took advantage of this opportunity, calling the project a review rather than a cancellation sounds better psychologically.

The dean of libraries also began creating materials to share with liaisons and faculty. She developed a LibGuide, available at http://libraryguides.salisbury.edu/journalreview, which included a detailed description of the process and timeline for the project, a memo for faculty, information on why some of the journals needed to be cut, Frequently Asked Questions, and what the future looked like for the SU Libraries despite these current cuts. This guided the liaisons through the process and also served as a valuable resource that they could refer faculty members to in later stages to help explain the history of the project. 
Two of the most important pieces the dean created were graphs. The first compared the growth in serials prices for ISI titles, as published in Library Journal each year, to the Consumer Price Index and the Higher Education Price Index from 1994 to 2014, clearly demonstrating how serials price increases far outpaced inflation. See Figure 1.

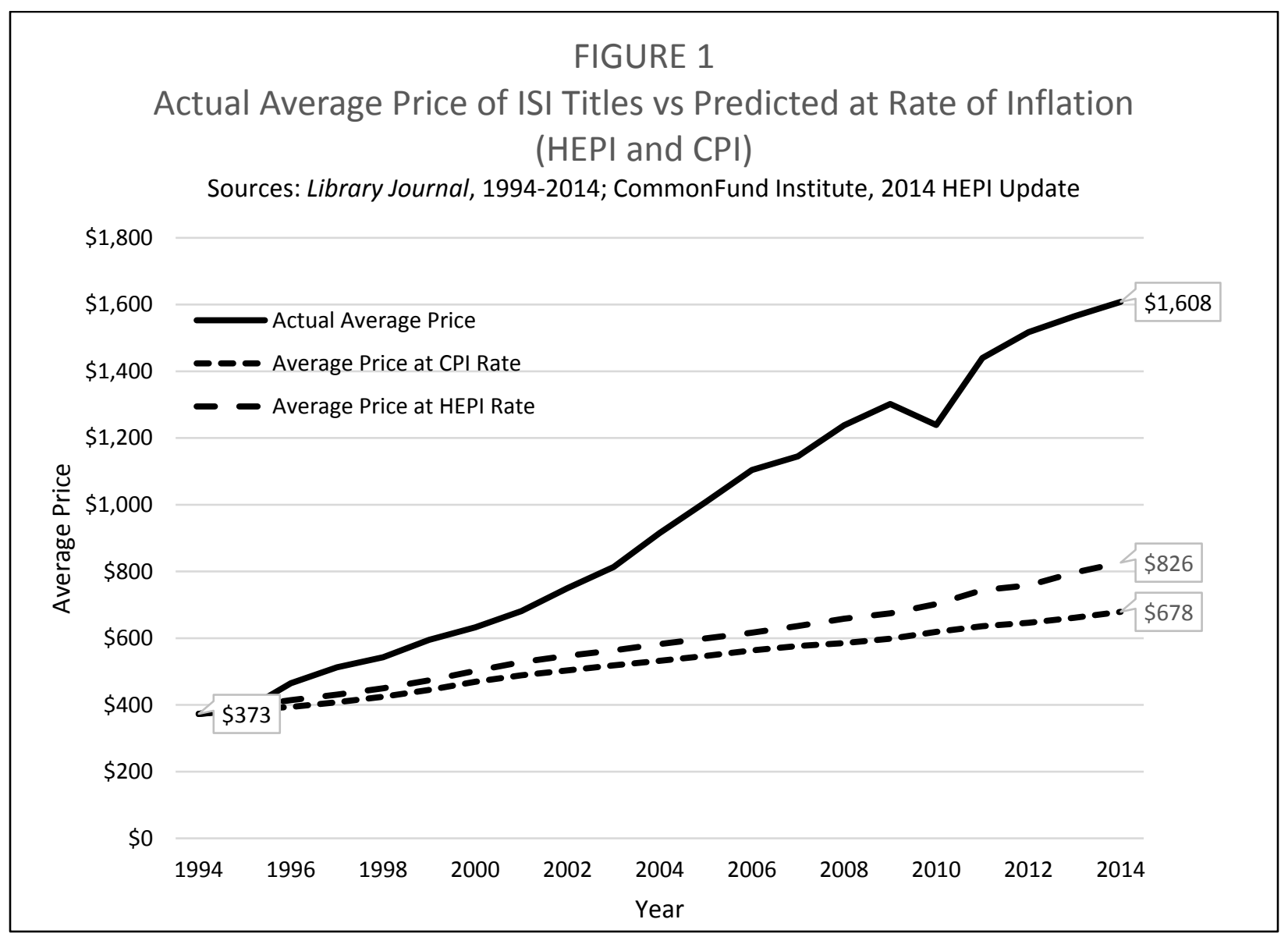

The second showed how journal and database spending had grabbed an ever-larger share of the nonpersonnel budget from 2006 to 2014. See Figure 2 . 


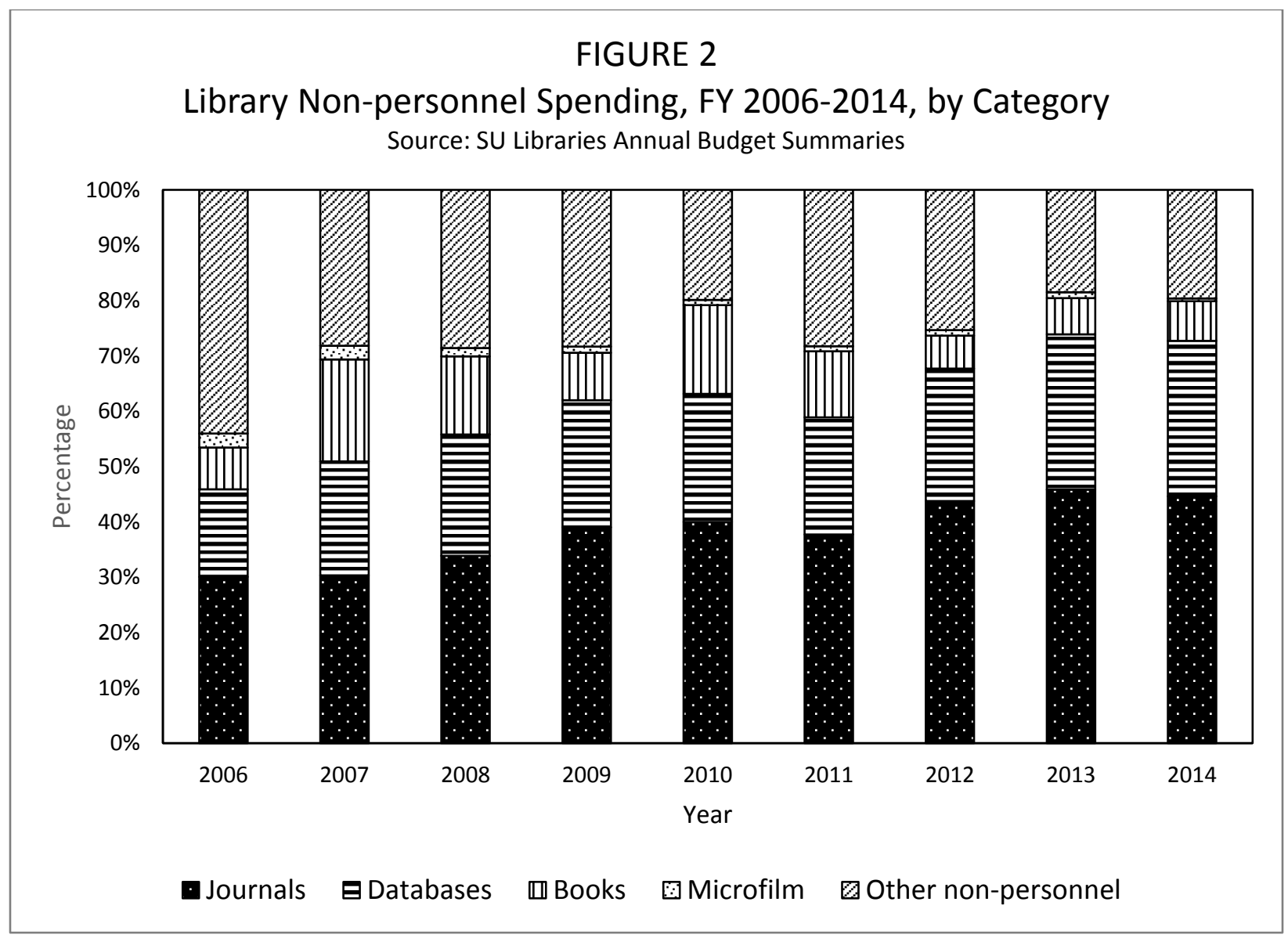

These visual representations of the data clarified the financial position of the Libraries and were very effective tools in helping faculty understand and appreciate why cuts were necessary.

\section{Getting Feedback: Liaison Input}

Liaison librarians were to provide input relating to both databases and journals. For databases, they were to consider all the databases listed in the database master spreadsheet and provide comments and suggestions about which ones to cancel or why specific databases needed to be kept despite high cost per use. Five liaisons provided feedback on the databases, and there fortunately was widespread agreement about which databases could be cut without hurting our users. 
In relation to journals, the liaisons were responsible for deciding which journals in their subject areas should be added to the review list that would be shared with faculty. Once the director of collection management and the scholarly communications librarian finished entering data in the journal master spreadsheet, they considered what format would best help the liaisons in determining which titles to nominate for review. They decided that in addition to providing the master spreadsheet, the scholarly communications librarian would create subject-specific spreadsheets based on fund codes. These sheets would have a built-in formula so that for each title a liaison selected for review, the spreadsheet would calculate how close that selection brought them to the reduction goal for that subject.

To help to determine which titles to nominate, liaisons considered some core concerns such as: was the title a requirement for accreditation; was the title available in a database, and, if so, the liaison was to note the source and dates of coverage; and how important was the journal considered in the discipline. Clearly, if a title was a requirement for accreditation, it must be kept, regardless of the cost or usage level. If a title was available in a database, this may have made it a more attractive option to nominate, as the University would not be losing complete access to that journal's contents, but at worst only have a delay in accessing the most recent material. As to the importance of the journal, in some disciplines this may be roughly determined by the journal's impact factor; another way of gauging importance was if it was used heavily in a department's research and/or teaching. Some liaisons relied primarily on the usage statistics and costs to narrow down the titles. Others involved faculty members in discussions at this point and this faculty input played a larger role in their decisions. As the liaisons have the most department-specific knowledge on the Libraries staff, they were best placed to come up with the first "short list" in the way that was most appropriate for their disciplines. 
In some cases, the task force decided that a department should not have to nominate any titles at all.

For example, the Physics Department only had four titles assigned to its fund code, and all of them were heavily used. Also, smaller departments such as Theatre \& Dance and Conflict Resolution had so few titles supporting them that it did not seem fitting to reduce them further.

\section{Getting Feedback: Faculty and Departmental Input}

Once the liaisons nominated titles for review, the task force members discussed the best way to share this information with faculty. They agreed that in this case, less was more. Where some of the statistics in the liaisons' spreadsheet were useful in making a first pass, the level of detail was bound to create potential roadblocks in getting feedback quickly from departments and faculty. Therefore, the task force decided that the spreadsheets shared with faculty would include only Title, Print ISSN, Online ISSN, Fund Code, Cost, and Database Coverage. If a faculty member wanted to see more information, the liaison could then share the more detailed spreadsheet with them in a one-on-one meeting.

After the task force had decided on the process and the liaisons had narrowed the list of candidates for review, we were ready to start soliciting faculty feedback. The dean met with all academic department chairs at their beginning-of-spring-semester meeting to inform them about what to expect. She also did a brief presentation to the Faculty Senate, where the graphs made a huge impact. The Faculty Senate president, in fact, chose to send them out to the entire faculty.

Liaisons then sent out a memo from the dean of libraries explaining the project to their department chairs along with the concise, subject-specific list of journals for review. The chairs were free to determine the best way to collect feedback from their faculty at this level. These lists were also made available in MyClasses, the University's learning management system, and liaisons encouraged individual 
faculty, in person and via email, to view the list for their department as well as the lists for any other departments whose journals they used regularly and then provide feedback. The dean followed up with an email to all faculty about a week after the liaisons had contacted their departments and sent a reminder a few days before the deadline.

MyClasses included a link to an online survey that individual faculty could fill out. The survey allowed respondents to rank each journal as essential, useful, or minimally useful and asked them to explain their reasons for any ranking of essential. To allow for interdisciplinary feedback, respondents could choose to rank journals from other departments in addition to their own, an option many took.

\section{Making the Decision and Sharing Results}

Once the survey closed, the dean and the director of collection management met to make the final decision about what databases and journals to cancel. The liaisons who responded had achieved some consensus about which databases should be cut, so that decision was easy. We cut three databases that the liaisons recommended but kept one where we share the cost with another campus unit.

In considering what journals to cancel, faculty feedback was important. Thirteen departments provided formal written feedback ranking the proposed journals, and others provided informal feedback to their liaisons. Some ninety-six faculty filled out the online survey. The online survey included separate questions for each title being considered for cancellation; consequently, the spreadsheet of responses was quite cumbersome, with more than two hundred columns. The dean consolidated the responses for each journal into one note field per title, incorporating both the rankings and any comments made about the title. The faculty comments about what journals were or were not valuable and how they used journals proved especially valuable. 
The dean and the director of collection management reviewed each title, looking at usage, cost, coverage in databases, and faculty responses. Faculty responses were the single most important factor influencing the decision to keep or cancel. The criteria used included:

1. If a department or multiple faculty rated a journal as essential, we kept it.

2. If only one faculty member rated a journal as essential, we looked at the explanation they provided for why it was essential. If the faculty member provided a good explanation, such as using it for an assignment or being required for accreditation, we kept it. If the explanation was not persuasive, we looked at how other faculty rated it; if anyone else rated it useful, we kept it.

3. If the journal dealt with diversity in some way, we tended to keep it, unless the faculty rated it minimally useful. Resources on diverse populations and cultures are not a collection strength at Salisbury, and we were leery of weakening them.

4. All other journals were cancelled.

In all, we cancelled 146 journals, along with the three databases, saving a total of $\$ 116,500$. This was less than our goal of $\$ 150,000$, but the task force believed that any additional cancellations would hurt our users. In addition, the president of the university took notice of the journal review project and promised to look at securing some additional funding for the SU Libraries.

The dean of libraries shared the cancellation list first with the Libraries staff and then the deans and vice presidents. She then sent an email with the cancellation list to all faculty and staff, thanking them for their input. Several faculty actually contacted us to thank us for the opportunity to provide feedback, and no faculty members have complained-at least not to us-about the cancellations.

\section{Lessons Learned?}


1. Keep it simple, especially for the faculty. Do not use library jargon while talking with them about the review. Make it easy for them to provide their input.

2. Have a good communication plan, both internally and externally. Cancelling journals can be upsetting, but be honest about what you are doing, why it is necessary, and how decisions will be made, and then share this information widely. That can go a long way towards calming fears.

3. Visual aids are very effective in helping people understand why cuts are necessary. When people saw the graph illustrating the increases in serials prices far above the rate of inflation, they stopped questioning why the Libraries needed to reduce the number of subscriptions.

4. Get feedback from departments as well as individuals. Having feedback from departments about what was important to them as a unit tempered instances where one or two faculty members rated highly journals that were important to them personally but that might not have been important at all for supporting the department's teaching. Also, several individual faculty members rated every journal in their department as essential, so having the departmental feedback gave us a better gauge.

5. Involve liaison librarians. The involvement of the liaison librarians allowed us to customize our approach for each department, which was valuable given the potential sensitivity of the project. It also allowed us to provide the appropriate amount of data for each department, as determined by the liaison: we shared more data with some departments, but in cases where too much data would only serve to distract or go unnoticed, we shared less.

The liaison librarians also benefited from this collaboration in several ways. The detailed exposure to the high price of this specific type of material helped to generate a deeper appreciation of some of the challenges the serials staff faces. Many of the liaisons were aware of the "serials crisis," but when confronted with the costs of journals for their departments and given the task to recommend which ones should first be looked at for cancellation, the crisis became real to them in a very tangible way. 
Also, they now understood the frustration administrators and serials staff feel with titles that, despite high cost and low usage (and in many cases, no usage at all in the past two years), could not be cancelled due to bundle deals or other kinds of contracts.

Participation in this project also helped the liaisons to better understand their departments' needs and behaviors with regards to journals and provided the opportunity to educate faculty in their departments about the high costs involved in providing journal materials. The first will serve us well if future budgets allow us to expand our collections. The second is important for the scholarly communications landscape as a whole. As faculty members are the authors of journal content, they have a vital role in the current publishing process and great influence on whether or not the "serials crisis" will continue.

Serials cancellation projects are, unfortunately, a reality for many libraries and likely to continue to be so for years to come. With proper planning and communication, however, they do not have to be a miserable experience and can even have some benefits beyond improving the library's finances. 
${ }^{1}$ Paul Metz, "Thirteen Steps to Avoiding Bad Luck in a Serials Cancellation Project," Journal of Academic Librarianship 18, no. 2 (1992): 76-82.

${ }^{2}$ Suzanne Wise, "Making Lemonade: The Challenges and Opportunities of Forced Reference Serials Cancellations: One Academic Library's Experiences," Serials Review 19, no. 4 (1993): 15-27, Academic Source Complete, EBSCOhost [accessed 4 January 2016].

3 Janice M. Jaguszewski and Laura K. Probst, "The Impact of Electronic Resources on Serial Cancellations and Remote Storage Decisions in Academic Research Libraries," Library Trends 48, no. 4 (2000): 799-821.

${ }^{4}$ Ronadin Carey, Stephen Elfstrand, and Renee Hijleh, "An Evidence-Based Approach for Gaining Faculty Acceptance in a Serials Cancellation Project," Collections Management 30 (2005), no. 2: 59-72.

${ }^{5}$ Ryan O. Weir, "Trimming the Library Materials Budget: Communication and Preparation as Key Elements," Serials Review 36, no. 3 (2010): 147-151, Academic Source Complete, EBSCOhost [accessed 4 January 2016].

${ }^{6}$ UNCW Randall Library, "Serials Review and Reduction Project 2009/2010," http://library.uncw.edu/book/export/html/740 [accessed 25 January 2016].

${ }^{7}$ Colgate University Libraries, "Colgate University Libraries Serials Review and Cancellation Project Spring 2009," http://exlibris.colgate.edu/collectionDevelopment/SerialsCancellations09.html [accessed 25 January 2016].

${ }^{8}$ North Carolina State University Libraries, "Collections and Journals Cancellation Review 2014," http://www.lib.ncsu.edu/collections/collectionsreview2014 [accessed 25 January 2016]. 